\title{
Global deformation from the great 2004 Sumatra-Andaman Earthquake observed by GPS: Implications for rupture process and global reference frame
}

\author{
Corné Kreemer, Geoffrey Blewitt, William C. Hammond, and Hans-Peter Plag \\ Nevada Bureau of Mines and Geology, and Seismological Laboratory, University of Nevada, Reno, MS 178, NV 89557-0088, U.S.A
}

(Received June 30, 2005; Revised October 17, 2005; Accepted November 9, 2005; Online published February 17, 2006)

\begin{abstract}
Static coseismic offsets $>1 \mathrm{~mm}$ are observed up to $7800 \mathrm{~km}$ away from the great Sumatra-Andaman earthquake of 26 Dec. 2004 using global GPS network data. We investigate the rupture process based on far-field continuous GPS data. To reduce error in the coseismic offset estimates due to post-seismic deformation in the days following the main shock, we simultaneously fit a model of co- and postseismic offsets for nearby stations SAMP $(500 \mathrm{~km})$ and NTUS $(900 \mathrm{~km})$. The 3-month cumulative postseismic displacement for station SAMP amounts to $20 \%$ of the coseismic displacement, and can be well modeled by velocity-strengthening afterslip. We find that coseismic slip on the northern rupture segment is $\sim 3 \mathrm{~m}$, which is consistent with seismic estimates. Our best estimate of the moment magnitude is $M_{w}=9.13$ if we take into account the expected increase of the shear modulus with depth (for uniform $\mu=30 \mathrm{GPa}$, the moment-magnitude would only be 8.97). Our geodetic results, and thus our inferred rupture model, are different from a similar study using far-field data of Banerjee et al. (2005). These differences highlight the challenge in earthquake studies on a global scale in terms of the sensitivity of far-field offset estimates to the analysis strategy and reference frame treatment. Our predicted coseismic offsets from this event are at least $1 \mathrm{~mm}$ across almost the entire globe. This warrants a reconsideration of how to maintain the global terrestrial reference frame affected by earthquakes of $M_{w}>9.0$.
\end{abstract}

Key words: GPS, Great Sumatra-Andaman Earthquake, earthquake rupture, coseismic displacements, postseismic deformation.

\section{Introduction}

The great Sumatra-Andaman earthquake of 26 December, 2004 is the first earthquake to be observed by modern geodetic techniques across the globe. This event provides unprecedented opportunities to study such an earthquake on a global scale, to verify our geodetic and geophysical models, and to infer solid earth deformation processes on a large range of time and spatial scales.

Much debate has occurred on the magnitude estimate of this earthquake using seismologic data. The original broad-band estimate from the Harvard CMT project was $M_{w}=9.0$. The initial analysis of the Earth's free oscillations yielded $M_{w}=9.3$ (Stein and Okal, 2005). Both estimates have since then been revised; long period analysis is now consistent with $\sim M_{w}=9.2$ (Lay et al., 2005), and a revision of the free oscillation analysis is now consistent with $M_{w}=9.15$ (Park et al., 2005). The time that was needed for the different analyses to converge towards a consistent value leaves room for much improvement. Spacegeodesy can provide an independent, and potentially (near) real-time, magnitude estimate. Also, GPS can provide additional constraints on the rupture process. Current estimates from seismology can vary significantly depending on the choice of analysis (Ammon et al., 2005).

Limited analysis of the time-series of SAMP and NTUS

Copyright (c) The Society of Geomagnetism and Earth, Planetary and Space Sciences (SGEPSS); The Seismological Society of Japan; The Volcanological Society of Japan; The Geodetic Society of Japan; The Japanese Society for Planetary Sciences; TERRAPUB. was presented by (Khan and Gudmundsson, 2005). A much more detailed study was presented by Vigny et al. (2005), who used a large amount of regional data (and some from far-field IGS stations) to put strong constraints on the extend and total slip along the rupture. Their analysis was, however, hindered by not taking into account possible postseismic offsets for continuous sites in the 14 days after the event, and by using an elastic half-space model instead of a spherical model approach.

In this study we focus on the ability to put constraints on the rupture process using far-field GPS static offsets. We focus on far-field offsets, because an $M_{w}>9.0$ event will create offsets over a large part (or all) of the globe such that the offset estimates are particularly sensitive to analysis approach (e.g., common-mode analysis) and reference frame treatment. Many other future subduction zone earthquakes are located in regions where only far-field data will be available. Banerjee et al. (2005), hereafter referred to as BPB, analyzed the time-series of 41 mainly far-field stations. They showed millimeter static offsets at GPS stations thousands of kilometers away from the earthquake rupture. We also calculate far-field static offsets, but using a different processing technique and applying a different analysis approach. Straight-forward estimates of static offsets from time-series for stations near the rupture are problematic, because of possible rapid postseismic deformation. We offer an alternative treatment of the time-series for those stations; i.e. SAMP and NTUS. 


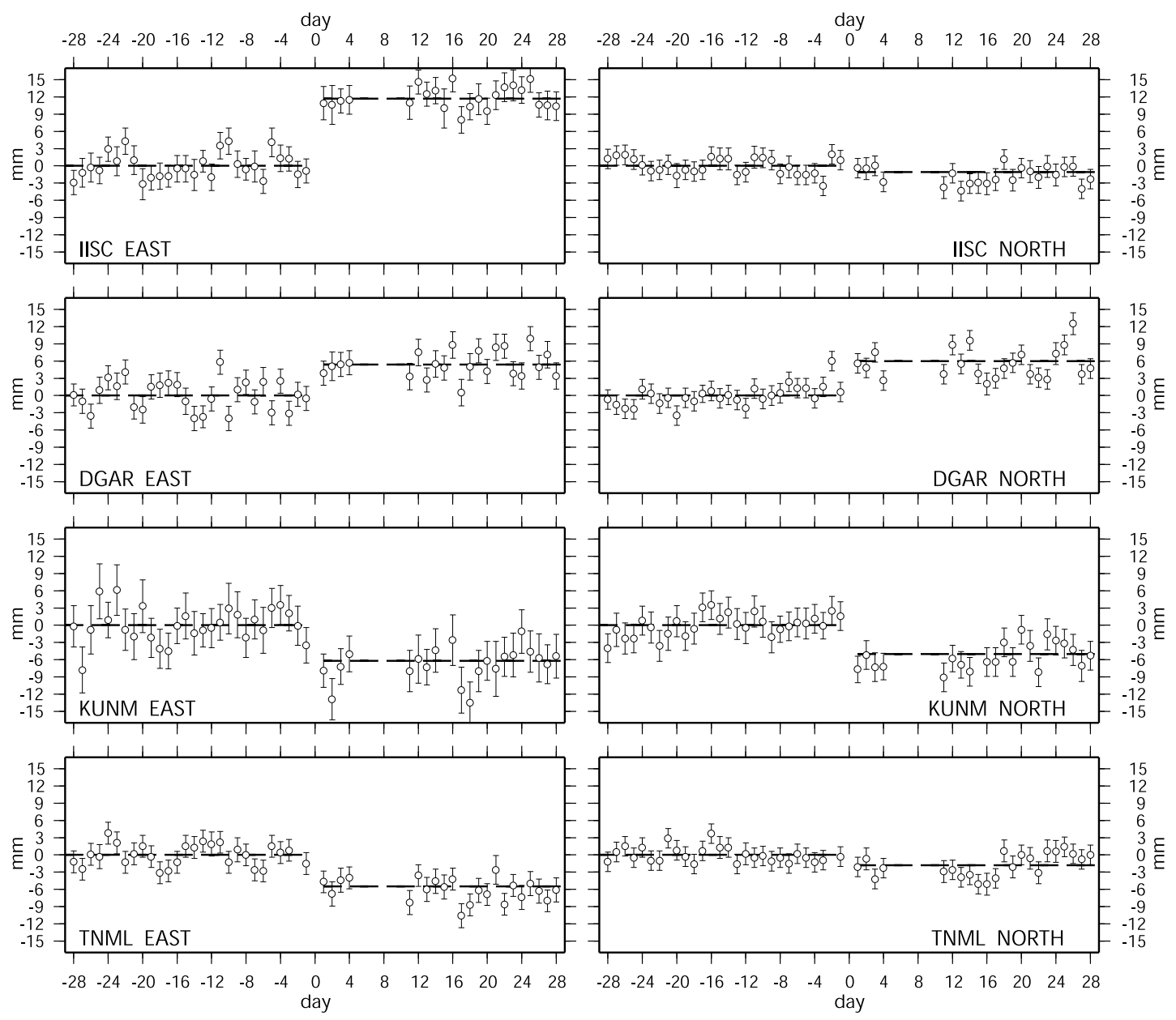

Fig. 1. Time-series of east and north components of the daily positions for four representative stations (IISC, DGAR, KUNM, TNML). Days are relative to December 26, 2004 (day 0). Error-bars are formal 1-sigma uncertainties. Time-series have been detrended using the secular station velocity, and are shown here relative to the average position (dashed line) of the 28 days before December 26, 2004. The average position (dashed line) of the 28 days after the earthquake is indicated as well, and is reported for all stations in Table 1.

\section{Data}

GPS data from 1 January 2000 to 27 March 2005 were processed from 27 stations within $7800 \mathrm{~km}$ of the rupture zone using the GIPSY OASIS II software package from the Jet Propulsion Laboratory (JPL). All stations are part of the network maintained by the International GPS Service (IGS), except SAMP, which is maintained by the BAKOSURTANAL Indonesian network. Station coordinates were estimated every 24 hours using the precise point positioning method (Zumberge et al., 1997) with ambiguity resolution applied successfully across the entire network by automatic selection of the ionospheric- or pseudorangewidelane method (Blewitt, 1989). Satellite orbit and clock parameters, and daily coordinate transformation parameters into the global reference frame (ITRF2000) were provided by JPL. Ionosphere-free combinations of carrier phase and pseudorange were processed every 5 minutes. Estimated parameters included a tropospheric zenith bias and two gradient parameters estimated as random-walk processes, and station clocks estimated as a white-noise process.

Station velocities were estimated using all available data from 1 January 2000 to 25 December 2004 (with most stations providing data for the entire period). These velocities were then used to detrend all the data (through 27 March
2005). To reduce the impact of coseismic displacements on the reference frame, all daily solutions were then transformed (by a 7-parameter Helmert transformation) onto the constant velocity solution using only stations $>4000 \mathrm{~km}$ from the epicenter. Formal errors for daily station positions were computed assuming 10-mm 1-standard deviation errors in the ionosphere-free carrier phase data. These errors were then realistically scaled by a factor of 2.1 (to normalize the reduced $\chi^{2}$ of the fit to the constant velocity model). 2.1 Time-series

To estimate the static coseismic displacements we calculated the difference between the average position for 28 days before and 28 days after the earthquake. The daily solution for 26 December, 2004 was not used. For the two closest stations, SAMP and NTUS, we followed a different procedure (see Section 2.2). We show the daily east and north positions for this time interval for stations IISC, DGAR, KUNM, and TNML (Fig. 1). These are indicative time-series, and similar data were also shown by BPB from their analysis.

\subsection{Postseismic afterslip}

The time-series of stations SAMP and NTUS indicate a non-linear trend after the earthquake (Fig. 2). Therefore, to properly estimate the coseismic displacements for these 


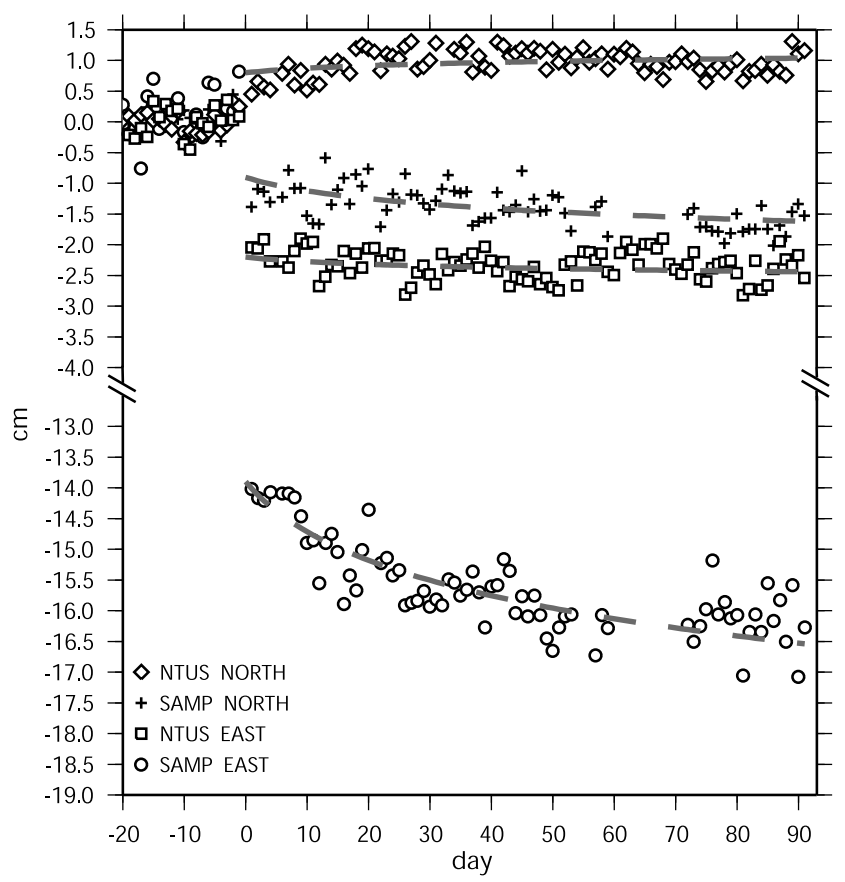

Fig. 2. Detrended time-series of the east and north components of the daily positions for stations NTUS and SAMP relative to the average position of the 20 days before December 26, 2004 (day 0). Shown are the results of a simultaneous solution for the best-fitting coseismic offsets (Table 1) and a logarithmic decay function (dashed lines) assuming that the postseismic displacements are due to afterslip.

stations, we use a method different from that applied to the other far-field stations. GPS postseismic time-series after other (subduction-type) earthquakes have been analyzed elsewhere to evaluate different possible mechanisms that could explain the data (e.g., Melbourne et al., 2002). Studies have found that afterslip occurring down-dip from the rupture plane is the dominant mechanism for subduction zone thrust events in Kamchatka and the Japan Trench (e.g., Heki et al., 1997; Bürgmann et al., 2001). For the December 26, 2005, event Vigny et al. (2005) noted that the apparent logarithmic decay in the time-series of regional GPS sites suggested that the postseismic deformation may indicate an afterslip process.

For SAMP and NTUS we have used the times-series from 20 days before 26 December, 2004 until 27 March, 2005 (i.e., the day before the $M_{w}=8.7$, Northern Sumatra event) to simultaneously solve for the horizontal coseismic offsets and a logarithmic function describing the afterslip process after the event (Fig. 2). The 20 days prior to the event are used to constrain an average pre-seismic position. The inferred coseismic offsets are reported in Table 1. For the postseismic time-series we fit the following function for each station: $\bar{u}=\bar{a} \ln (b t+1)$ (Marone et al., 1991). Here, $b$ is the decay constant, and we solve for a single $b$ value using the four time-series (east and north) of both stations. We find that $b=0.11 \mathrm{day}^{-1}$, or $40.2 \mathrm{yr}^{-1}$, which implies that $\sim 65 \%$ of the postseismic displacements expected within the first year has occurred within the 91 days that we analyzed after the earthquake. For our best-fit model we find $a(x)=-11 \mathrm{~mm}$ and $a(y)=-3 \mathrm{~mm}$ for SAMP, and $a(x)=-1 \mathrm{~mm}$ and $a(y)=1 \mathrm{~mm}$ for NTUS.
Table 1. GPS-derived coseismic offsets.

\begin{tabular}{crrrrrrr}
\hline Site & $\begin{array}{r}\text { Lon. } \\
\left({ }^{\circ} \mathrm{E}\right)\end{array}$ & $\begin{array}{r}\text { Lat. } \\
\left({ }^{\circ} \mathrm{N}\right)\end{array}$ & $\begin{array}{r}\mathrm{D} \\
(\mathrm{km})\end{array}$ & $\begin{array}{r}\Delta_{\text {east }} \\
(\mathrm{mm})\end{array}$ & $\begin{array}{r}\Delta_{\text {north }} \\
(\mathrm{mm})\end{array}$ & $\begin{array}{c}\sigma_{\text {east }} \\
(\mathrm{mm})\end{array}$ & $\begin{array}{c}\sigma_{\text {north }} \\
(\mathrm{mm})\end{array}$ \\
\hline ALIC & 133.9 & -23.7 & 5220 & -1.9 & 1.1 & 0.4 & 0.4 \\
BAHR & 50.6 & 26.2 & 5313 & 0.1 & 2.5 & 0.4 & 0.4 \\
BAKO & 106.8 & -6.5 & 1757 & 2.3 & 3.7 & 1.3 & 0.6 \\
COCO & 96.8 & -12.2 & 1722 & 1.3 & 4.9 & 0.6 & 0.4 \\
DARW & 131.1 & -12.8 & 4440 & -3.6 & 0.8 & 0.6 & 0.4 \\
DGAR & 72.4 & -7.3 & 2688 & 5.4 & 6.0 & 0.6 & 0.4 \\
GUAM & 144.9 & 13.6 & 5677 & -4.2 & 2.3 & 0.6 & 0.4 \\
HRAO & 27.7 & -25.9 & 7841 & 1.5 & -0.4 & 0.6 & 0.6 \\
HYDE & 78.6 & 17.4 & 2340 & 5.8 & -1.4 & 0.6 & 0.4 \\
IISC & 77.6 & 13.0 & 2142 & 11.7 & -1.1 & 0.6 & 0.4 \\
KARR & 117.1 & -21.0 & 3654 & -1.9 & 2.3 & 0.6 & 0.4 \\
KIT3 & 66.9 & 39.1 & 4870 & 1.0 & 1.1 & 0.6 & 0.6 \\
KUNM & 102.8 & 25.0 & 2605 & -6.2 & -5.0 & 1.1 & 0.6 \\
LAE1 & 147.0 & -6.7 & 5953 & 1.9 & -2.0 & 0.8 & 0.6 \\
LHAS & 91.1 & 29.7 & 2973 & -1.1 & -1.3 & 0.8 & 1.1 \\
MALI & 40.2 & -3.0 & 6047 & 2.0 & 0.7 & 0.8 & 0.6 \\
MBAR & 30.7 & -0.6 & 7072 & 1.4 & 0.5 & 0.6 & 0.4 \\
MALD & 73.5 & 4.2 & 2304 & 9.9 & 4.0 & 1.1 & 0.6 \\
NTUS ${ }^{1}$ & 103.7 & 1.3 & 1064 & -22.0 & 8.0 & 0.6 & 0.4 \\
PIMO & 121.1 & 14.6 & 3208 & -7.9 & 0.7 & 0.6 & 0.6 \\
REUN & 55.6 & -21.2 & 5003 & 1.6 & 3.7 & 1.3 & 0.6 \\
SAMP 1 & 98.7 & 3.6 & 498 & -139.0 & -9.0 & 1.1 & 0.6 \\
SEY1 & 55.5 & -4.7 & 4394 & -3.5 & -3.1 & 0.8 & 0.4 \\
TNML & 24.8 & 121.0 & 3744 & -5.5 & -1.8 & 0.6 & 0.4 \\
TOW2 & 147.1 & -19.3 & 6281 & 1.6 & -0.7 & 0.6 & 0.4 \\
WUHN & 140.1 & 36.1 & 5956 & -2.6 & -1.8 & 0.4 & 0.6 \\
& & 30.5 & 3711 & -3.9 & -1.9 & 0.6 & 0.6 \\
\hline
\end{tabular}

$\mathrm{D}$, distance from site to epicenter.

1 our coseismic offsets for SAMP and NTUS are determined simultaneously with parameters for a postseismic afterslip process (see Fig. 2). The uncertainties for these sites were determined similarly to those of other sites.

The 3-month cumulative postseismic displacements represent $20 \%$ and $14 \%$ of the initial coseismic displacements for SAMP and NTUS, respectively.

\subsection{Coseismic displacements}

The inferred coseismic displacements are listed in Table 1 and shown in Fig. 3. Generally, displacements are towards the epicenter, with amplitude decaying with distance. The magnitude of the far-field displacements northeast and southwest of the rupture are greater than to the northwest and southeast, consistent with a thrust mechanisms along a $\sim$ northwest-southeast trending fault. For example the site TNML moves nearly twice the distance of KARR which has a similar epicentral distance.

Our results and those of BPB exhibit a similar general pattern. Although differences at any individual site may not be significant, some important systematic differences exist (Fig. 3). Our estimate for NTUS is more than 1.5 larger than that of BPB. For stations IISC, HYDE, and TNML, predicted directions between both studies are very close, but BPB offsets are $~ 130-170 \%$ larger. A similar discrepancy in rate also exists for PIMO, WUHN, DGAR, (and to lesser extent KUNM), however BPB estimates are all directed considerably more southward than our predicted directions. Also for stations LAE1, BAKO, and COCO are the BPB estimates directed more southward. For African 


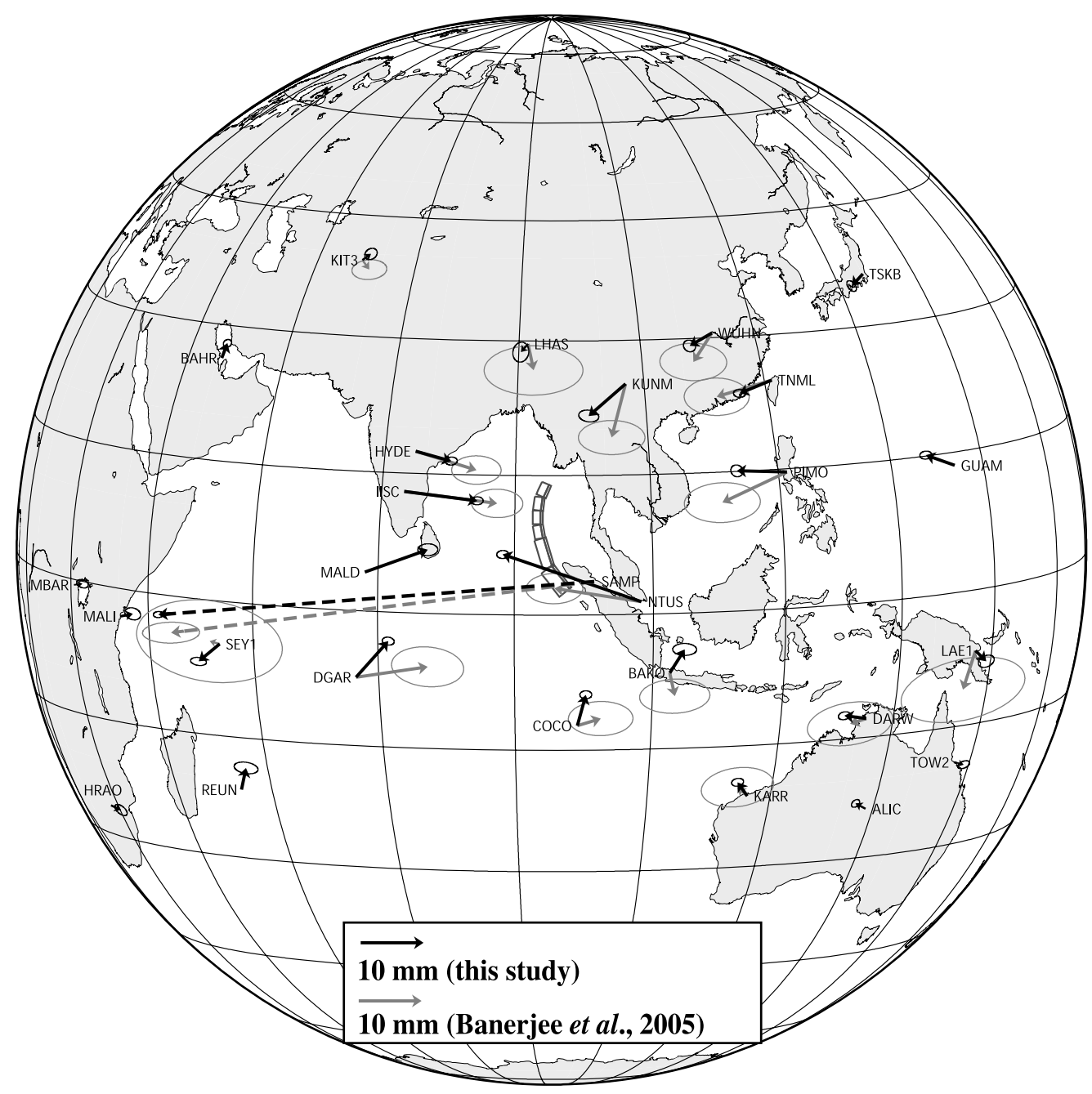

Fig. 3. Observed coseismic displacements from this study and Banerjee et al. (2005). Uncertainties are shown as $68 \%$ confidence ellipses. Rupture segments used in this study and by Banerjee et al. (2005) are shown in dark gray (there are shallow and deep segments). The dashed displacements for station SAMP are plotted at half the scale as the other vectors.

stations (for which BPB did not present estimates) we find consistent eastward offsets of $\sim 1.5-2.1 \mathrm{~mm}$.

\section{Rupture Model}

The far-field coseismic displacements are sensitive to the distribution of coseismic slip along the Indian-Burma plate boundary during the earthquake. For simplicity and comparison, we model the rupture as slip on planes identical to those found by BPB. The location and dip of the rupture planes is rather well supported by the seismicity (Engdahl et al., 1998; Lay et al., 2005). The difference between our far-field offsets and those of BPB requires changes in the rake and slip parameters inferred by BPB (their model M3). Like BPB, we use a layered spherical Earth model (Pollitz, 1996) and the PREM elastic stratification (Dziewonski and Anderson, 1981) to calculate static offsets. We use spherical harmonic degrees from $l=1$ to $l=1500$.

In the M3 model of BPB the fault rupture is divided into 3 segments. The northern segment has uniform slip up to 30 $\mathrm{km}$ depth only, with the segment divided along strike into four sub-segments, each with their own estimated rake. The central and southern segment each has one rake estimate, and has a deep (i.e., $30-50 \mathrm{~km}$ ) as well as shallow segment, each with similar slip offsets.

In our first model (A), we estimate the misfit between our observations and the predicted static offsets when we use the rake and slip estimates of BPB. We present our misfit in terms of $\chi_{v}^{2}$, which is the reduced $\chi^{2}$ (i.e., $\chi^{2}$ divided over $N-n$, with $N$ the number of data constraints, and $n$ the number of free model parameters) (Table 2). We will see next that the data fit for model A is relatively poor. Our coseismic observations imply therefore a considerably different rupture model than the one of BPB.

In our second model (B) we keep the rake estimates of BPB and solve for the slip offsets for the three segments such that the $\chi_{v}^{2}$ is minimized. Fault parameters are shown in Table 2. $\chi_{v}^{2}$ estimates are relatively insensitive to small variations in slip, therefore we find a range of model parameters that would result in roughly the same $\chi_{v}^{2}$. We use this range to assign uncertainties in our model parameters (Table 2).

In model $\mathrm{C}$ we solve simultaneously for slip offsets for the three segments, as well as for rake estimates for the four sub-segments of segment 1 , and for segment 2. Like BPB, we set the rake for segment 3 to $90^{\circ}$. For this model we find left-lateral oblique slip for Segment 1. This result is 
Table 2. Rupture model parameters and goodness of fit.

\begin{tabular}{ccccccccccc}
\hline Model & $\lambda_{1-a},{ }^{\circ}$ & $\lambda_{1-b},{ }^{\circ}$ & $\lambda_{1-c},{ }^{\circ}$ & $\lambda_{1-d},{ }^{\circ}$ & $\lambda_{2},{ }^{\circ}$ & $\lambda_{3},{ }^{\circ}$ & $U_{1}, \mathrm{~m}$ & $U_{2}, \mathrm{~m}$ & $U_{3}, \mathrm{~m}$ & $\chi_{v}^{2}$ \\
\hline A & 137 & 122 & 115 & 105 & 105 & 90 & 10.5 & 14.1 & 6.6 & 34.6 \\
B & 137 & 122 & 115 & 105 & 105 & 90 & $3.1 \pm 0.5$ & $12.5 \pm 0.7$ & $6.0 \pm 0.2$ & 19.9 \\
C & $50 \pm 10$ & $50 \pm 10$ & $50 \pm 10$ & $50 \pm 10$ & $104 \pm 1$ & 90 & $3.3 \pm 0.1$ & $11.3 \pm 0.3$ & $5.9 \pm 0.1$ & 17.0 \\
D & 90 & 90 & 90 & 90 & $104 \pm 1$ & 90 & $3.3 \pm 0.1$ & $11.3 \pm 0.3$ & $5.9 \pm 0.1$ & 16.9 \\
\hline
\end{tabular}

$\lambda$, rake; $U$, slip. Subscripts 1-3 indicate north to south segments of Banerjee et al. (2005), and a-d are north to south sub-segments of segment 1. $\chi_{v}^{2}$ is the reduced $\chi^{2}$

Model parameters in italics are fixed, values in bold are solved for in this study. Model A is similar to model M3 of Banerjee et al. (2005). See text for descriptions of models B-D.

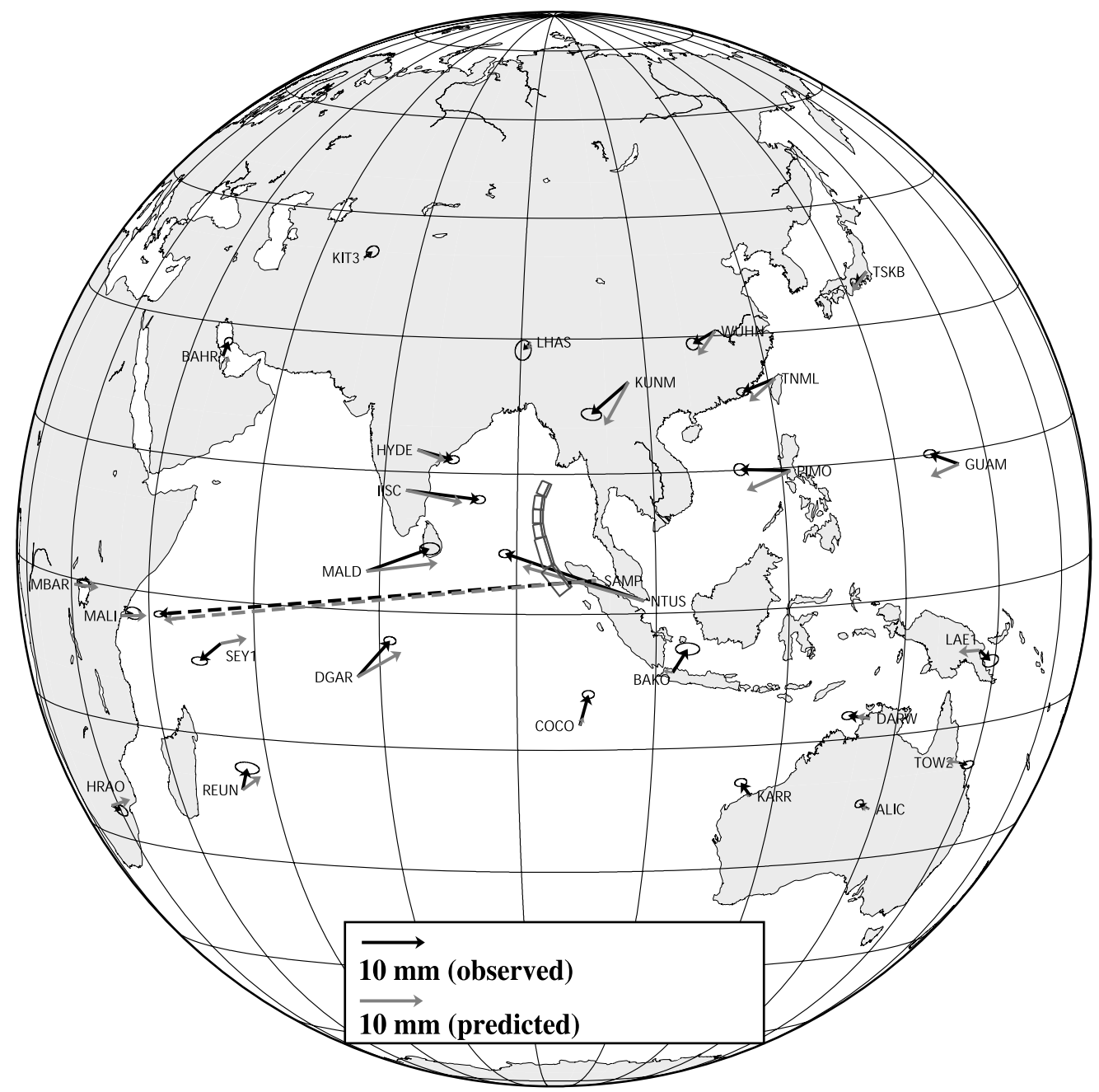

Fig. 4. Observed coseismic displacements from this study and predicted displacements from model C. Uncertainties in observed vectors are shown as $68 \%$ confidence ellipses. Rupture segments are shown in dark gray. The dashed displacements for station SAMP are plotted at half the scale as the other vectors.

not compatible with the seismotectonic context and is also inconsistent with slip vectors of aftershocks along the Andaman segment inferred from the Harvard CMT solutions. Therefore, in our final model D, we constrain the rake of the sub-segments of Segment 1 to pure dip-slip. We find that the $\chi_{v}^{2}$ for model $\mathrm{C}$ is larger than for model $\mathrm{D}$, thus solving for the rakes on Segment 1 does not improve the fit. To evaluate whether our fit for model $\mathrm{D}$ is a significant improvement over the fit for model B, we perform an F-test and find the improvement to be significant. Thus although our data cannot distinguish between models with dip-slip or left-lateral oblique slip on Segment 1, our data precludes right-lateral oblique slip, as found by BPB. Our predicted offsets for model D are shown in Fig. 4 together with our coseismic offsets.

\section{Discussion \\ 4.1 Revised rupture interpretation}

There are two main differences between the rupture models we inferred here from our coseismic observations and the models of BPB. First, we find only $\sim 3 \mathrm{~m}$ offset on Segment 1, which is much lower than the $10.5 \pm 0.5$ for BPB's preferred model M3. This is a direct result of the fact that our coseismic offsets in India and Southeast Asia 
are much lower than their estimates. Our result is much more consistent with the $<2 \mathrm{~m}$ obtained for the Andaman (i.e., northern) segment from seismic modeling (Ammon $e t$ al., 2005; Lay et al., 2005). Secondly, our data does not require oblique slip on the Andaman segment (however, it does for the Nicobar (middle) segment), as found by BPB.

All geodetic models on the earthquake rupture from both our study and BPB are in two major ways in disagreement with seismic models of the earthquake rupture (Ammon et al., 2005; Ishii et al., 2005; Krüger and Orhnberger, 2005) and other observations (Bilham et al., 2005). First, the seismic models suggest that the maximum peak in seismic energy or displacement is near northern Sumatra, and not near the Nicobar Islands where the segment with the highest slip (Segment 2) of the geodetic models is located. The geodetic results are more in agreement with the analysis of normal modes excited by the event. Those studies place the centroid at $7.5^{\circ}$ north latitude (Park et al., 2005; Stein and Okal, 2005), close to where the far-field coseismic offsets constrain the maximum slip to be, and significantly north of the CMT epicenter. Secondly, Bilham et al. (2005) inferred from vertical offset observations respectively 15-23 $\mathrm{m}$ and 5-10 $\mathrm{m}$ for slip along parts of the Nicobar and Andaman segments of the rupture, consistently more than our and BPB estimates for the Nicobar segment and our result for the Andaman segment. However, the large observed offsets are concentrated along only very small portions of the rupture (e.g., Simeulue Island) and such details are not resolvable using far-field offsets alone, but has been seen/modeled with regional GPS data (Vigny et al., 2005). For the southern segment geodetically derived estimates of $\sim 6 \mathrm{~m}$ are not inconsistent with the average $7 \mathrm{~m}$ found from seismic modeling (Lay et al., 2005). Clearly, to understand better, or resolve, the difference between the seismic and geodetic results, regional geodetic data is important (Vigny et al., 2005).

Some of the discrepancies noted above are expressed in the inferred moment magnitude between the different geodetic and geologic models. When using a shear modulus of $\mu=30 \mathrm{GPa}$, which is generally used for continental earthquakes, model $\mathrm{C}$ corresponds to an $M_{0}=3.63 \times 10^{22}$ $\mathrm{N}$ m, equivalent to $M_{w}=8.97$. This value is much lower than that of BPB or published seismic estimates derived from long-period broadband data (Lay et al., 2005) or free oscillations (Park et al., 2005; Stein and Okal, 2005). The only way to reconcile our moment estimate with the seismic estimates is to assume larger values for the shear modulus than $30 \mathrm{GPa}$. It has been shown (Bilek and Lay, 1999) that the shear modulus can increase significantly with depth along a subduction interface, with values lower than 30 $\mathrm{GPa}$ in unconsolidated sediments at very shallow depths, and values over $100 \mathrm{GPa}$ at $40-50 \mathrm{~km}$ depth. The PREM model also implies a depth increase of the shear modulus with depth. When we chose a permissible shear modulus of $40 \mathrm{GPa}$ as average for the $0-30$ depth segments, and 100 GPa as average for the 30-50 km depth segments (Bilek and Lay, 1999), we obtain $M_{w}=9.13\left(M_{0}=6.11 \times 10^{22} \mathrm{~N} \mathrm{~m}\right)$, which is very close to the $M_{w}=9.15$ from the latest analysis of free oscillations (Park et al., 2005). Thus, if our coseismic offsets, our rupture analysis, and the result by Park et al. (2005) are all reasonable, then our results indicate a significant increase of the shear modulus with depth, as expected. Improved knowledge of the shear modulus and its variation with depth (as well as other parameters that may vary between subduction zones) is therefore an important asset in magnitude determination using GPS. In any case, geodesy can provide important (near) real-time constraints on the earthquake size and thereby alleviate the difficulties to derive the magnitude quickly from seismology.

\subsection{Afterslip implications}

Our analysis of the postseismic time-series for NTUS and SAMP indicate that postseismic displacements are not subparallel to coseismic displacements. More specifically, for stations SAMP and NTUS the direction of postseismic offset is $\sim 10^{\circ}$ more southward and $\sim 20^{\circ}$ more northward, respectively, compared to the coseismic direction. That is, for SAMP postseismic displacements are directed more normal to southern rupture plane, and for NTUS more parallel to southern rupture plane, compared to coseismic offsets. Further north, near Phuket, Thailand, Vigny et al. (2005) found the post- and coseismic offsets to be parallel. Although our results are important to infer the actual afterslip process, particularly where it is occurring with respect to the rupture, we can not infer any more details on the afterslip process. Because of our emphasis on far-field GPS sites, and because postseismic processes are still ongoing as of this writing, we have not analyzed all the near-field geodetic data needed to definitively constrain postseismic afterslip in the vicinity of the rupture plane. However, our results suggest that after 1 year the postseismic displacement at SAMP and NTUS will be $30 \%$ and $23 \%$ of the coseismic displacement, respectively. This is relatively small compared to some cases observed elsewhere (e.g., Heki et al., 1997; Márquez Azúa et al., 2002), and is also small compared to our preliminary analysis of postseismic time-series after the $M_{w}=8.7$ March 28, 2005, event for which afterslip seems rapid and extensive (at SAMP $80 \%$ of coseismic offset is predicted to be accumulated as postseismic displacement 1 year after that event). The difference in postseismic offsets, and related afterslip processes, for the two Sumatra earthquakes may be explained, among several reasons, by the consideration that the rupture of the first event broke the surface, and the second did not. This would be consistent with the fact that the first event generated a large tsunami, and the second event did not. Moreover, it could explain the rapid afterslip we observe after the second event in terms of afterslip within the sediments up dip from the rupture.

\subsection{Implications on global geodetic reference frame}

We have shown that observed coseismic offsets are generally well above $1 \mathrm{~mm}$ at $7000 \mathrm{~km}$ from the earthquake rupture. We find from our model $\mathrm{C}$ that expected displacements are in fact $>1 \mathrm{~mm}$ for almost anywhere across the Earth's surface (Fig. 5). This has profound implications for the realization of the terrestrial reference frame, as station coordinates are currently being measured with $1 \mathrm{~mm}$-level precision. This reference frame problem only arises now because this is the first earthquake in history that has deformed the entire Earth's surface at a detectable level. The last earthquake of $M_{w}>9.0$ occurred $\sim 40$ years ago (in Alaska), well before modern space geodesy even existed. 


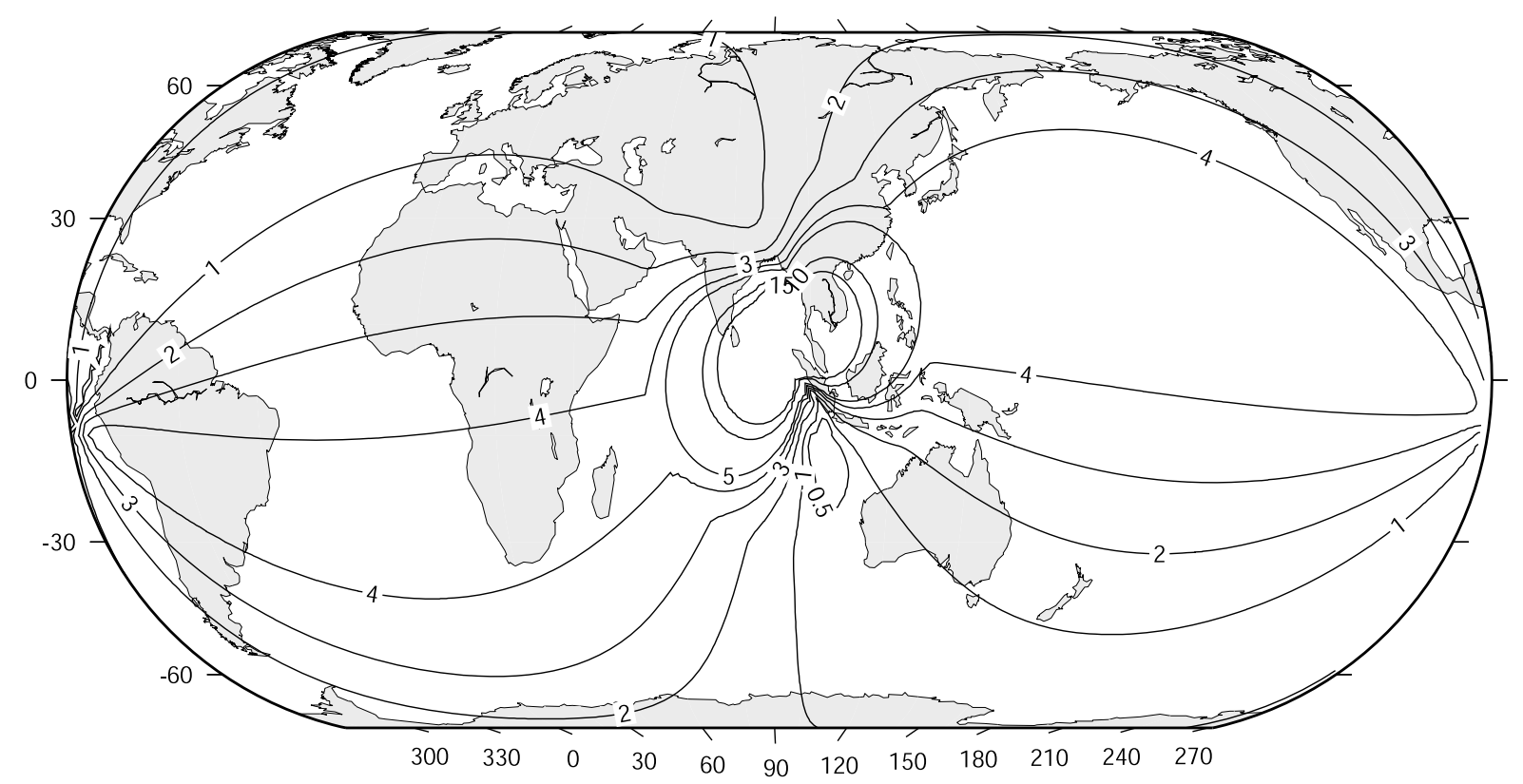

Fig. 5. Contours (in millimeters) of predicted total horizontal displacements from our coseismic model C. The expected displacements are $>1$ mm almost everywhere on the Earth's surface.

One immediate problem is to define the meaning of a coseismic offset when the entire Earth surface has moved coseismically. Prior to the 2004 Sumatra earthquake, the definition was simply in terms of how far a station had moved with respect to stations in the far field, where it was possible to find a station sufficiently far from the earthquake that its displacement was completely negligible. This is no longer the case. In our analysis, we have defined the reference frame in terms of the average position of stations more than $4000 \mathrm{~km}$ from the rupture, but this is clearly an ad hoc solution until clearer conventions are debated and agreed upon.

One rigorous solution we propose would be to use a model of the surface displacement in a reference frame that has no-net translation with respect to the modeled center of mass of the entire Earth (including the static ocean response), and no-net rotation with respect to the modeled Earth surface. Observed coseismic displacements could then be defined within a frame where there is no-net translation or rotation of the residual station coordinates (observed minus the modeled displacements). One challenge with this approach is that various models might explain the observed deformation to within the errors. Another challenge is that typically such models are adjusted to fit the data, and that care must be taken to ensure that this is done in a way that is self-consistent with the reference frame definition. A third challenge is that, as we have shown for some stations, coseismic offsets might represent only a fraction of the total station motion caused by the earthquake. And finally, for some far-field stations coseismic offsets may be of the same order of magnitude, or smaller, than the effects of possible station instability or incorrectly modeled tropospheric delay (see, for instance, the anomalous offset at SEY1).

A related problem is how to define the coordinates of the entire global geodetic network now that such a great earthquake has taken place. Clearly this relates to the above problem, in that offsets could be estimated within a modelspecific frame, and added to the pre-seismic coordinates. However, note that this requires that a conventional earthquake displacement model be selected (and clearly specified) in order to maintain a conventional international terrestrial reference frame. In principle, such a model should be specified for all great earthquakes. The process toward developing and agreeing upon a conventional model for every great earthquake would certainly be a challenge for the geodetic community.

\section{Conclusions}

We have estimated and analyzed coseismic static offsets of far-field GPS stations from the 26 December, 2004, earthquake. In this process we also found and analyzed significant postseismic displacements for nearby stations (specifically SAMP), which are consistent with a velocitystrengthening afterslip process. At many locations, our coseismic offsets are systematically different than those obtained by BPB. These differences are the result of using different analysis strategies and underscore the need for a conventional geodetic approach when dealing with displacements from an earthquake with $M_{w}>9.0$. The main difference between our rupture model and that of BPB is that we find a much lower slip on the northern rupture segment, which is more consistent with seismic studies. Consequently we find a much lower $M_{w}$ than BPB and, more importantly, than independent earthquake studies using free oscillations. The only way to resolve this difference is to use a significant increase in shear modulus with depth when estimating our seismic moment. We argue that an $M_{w}=9.13$ from our result is permissible. Our predicted coseismic offsets from this event are at least $1 \mathrm{~mm}$ across almost the entire globe. This warrants a reconsideration of how to maintain the global terrestrial reference frame affected by earthquakes of $M_{w}>9.0$. 
Acknowledgments. We thank F. Pollitz for his help and for making his spherical coseismic programs available, and two anonymous reviewers for comments on the manuscript. We are grateful to the International GPS Service and BAKOSURTANAL for making GPS data freely available and to the Jet Propulsion Laboratory for the GIPSY OASIS II software and precise GPS orbit products.

\section{References}

Ammon, C. J., C. Ji, H.-K. Thio, D. Robinson, S. Ni, V. Hjorleifsdottir, H. Kanamori, T. Lay, S. Das, D. Helmberger, G. Ichinose, J. Polet, and D. Wald, Rupture process of the 2004 Sumatra-Andaman earthquake, Science, 308, 1133-1139, 2005.

Banerjee, P., F. F. Pollitz, and R. Bürgmann, The size and duration of the Sumatra-Andaman earthquake from far-field static offsets, Science, 308, 1769-1772, 2005

Bilek, S. L. and T. Lay, Rigidity variations with depth along interplate megathrust faults in subduction zones, Nature, 400, 443-446, 1999.

Bilham, R., R. Engdahl, N. Feldl, and S. P. Satyabala, Partial and complete rupture of the Indo-Andaman plate boundary 1847-2004, Seismological Research Letters, 76, 299-311, 2005.

Blewitt, G., Carrier phase ambiguity resolution for the Global Positioning System applied to geodetic baselines up to $2000 \mathrm{~km}$, Journal of Geophysical Research, 94, 10,187-10,283, 1989.

Bürgmann, R., M. G. Kogan, V. E. Levin, C. H. Scholz, R. W. King, and G. M. Steblov, Rapid aseismic moment release following the 5 December, 1997 Kronotsky, Kamchatka, earthquake, Geophysical Research Letters, 28, 1331-1334, 2001.

Dziewonski, A. M. and D. L. Anderson, Preliminary reference Earth model, Physics of the Earth and Planetary Interiors, 25, 297-356, 1981.

Engdahl, E. R., R. van der Hilst, and R. Buland, Global teleseismic relocation with improved travel times and procedures for depth determination, Bulletin of the Seismological Society of America, 88, 722-743, 1998.

Heki, K., S. Miyazaki, and H. Tsuji, Silent fault slip following an interplate thrust earthquake at the Japan Trench, Nature, 386, 595-598, 1997.

Ishii, M., P. M. Shearer, H. Houston, and J. E. Vidale, Extent, duration and speed of the 2004 Sumatra-Andaman earthquake imagined by the Hi-Net array, Nature, 435, 933-936, 2005.

Khan, S. A. and O. Gudmundsson, GPS analysis of the Sumatra-Andaman earthquake, EOS Transactions, 86, 89-94, 2005.

Krüger, F. and M. Orhnberger, Tracking the rupture of the $M_{w}=9.3$ Sumatra earthquake over $1,150 \mathrm{~km}$ at teleseismic distance, Nature, $\mathbf{4 3 5}$, 937-939, 2005.

Lay, T., H. Kanamori, C. J. Ammon, M. Nettles, S. N. Ward, R. C. Aster, S. L. Beck, M. R. Brudzinski, R. Butler, H. R. DeShon, G. Ekström, K. Satake, and S. Sipkin, The Great Sumatra-Andaman earthquake of 26 December 2004, Science, 308, 1127-1133, 2005.

Marone, C. J., C. H. Scholz, and R. Bilham, On the mechanics of earthquake afterslip, Journal of Geophysical Research, 96, 8441-8452, 1991.

Márquez Azúa, B., C. DeMets, and M. Masterlark, Strong interseismic coupling, fault afterslip, and viscoelastic flow before and after the Oct. 9, 1995 Colima-Jalisco earthquake: Continuous GPS measurements from Colima, Mexico, Geophysical Research Letters, 29, 1281 doi:10.1029/2002GL014702, 2002.

Melbourne, T. I., F. H. Webb, J. M. Stock, and C. Reigber, Rapid postseismic transients in subduction zones from continuous GPS, Journal of Geophysical Research, 107, 2241, doi:10.1029/2001JB000555, 2002.

Park, J., T. A. Song, J. Tromp, E. Okal, S. Stein, G. Roult, E. Clevede, G. Laske, H. Kanamori, P. Davis, J. Berger, C. Braitenberg, M. van Camp, X. Lei, H. Sun, H. Xu, and S. Rosat, Earth's free oscillations excited by the 26 December 2004 Sumatra-Andaman earthquake, Nature, 308, 1139-1144, 2005.

Pollitz, F. F., Coseismic deformation from earthquake faulting on a layered spherical Earth, Geophysical Journal International, 125, 1-14, 1996.

Stein, S. and E. Okal, Speed and size of the Sumatra earthquake, Nature, 434, 581-582, 2005.

Vigny, C., W. J. F. Simons, S. Abu, R. Bamphenyu, C. Satirapod, N. Choosakul, C. Subarya, A. Socquet, K. Omar, H. Z. Abidin, and B. A. C. Ambrosius, Insight into the 2004 Sumatra-Andaman earthquake from GPS measurements in southeast Asia, Nature, 436, 201-206, 2005.

Zumberge, J. F., M. B. Heflin, D. C. Jefferson, and M. M. Watkins, Precise point positioning for the efficient and robust analysis of GPS data from large networks, Journal of Geophysical Research, 102, 50055017, 1997.

C. Kreemer (e-mail: kreemer@unr.edu), G. Blewitt, W. C. Hammond, and H.-P. Plag 